\title{
Characterization of Activated Carbon from Pyrolysis Process of Bamboo Base Waste (Dendrocalamus asper)
}

\section{Karakteristik Arang Aktif Hasil Pirolisis Limbah Pangkal Bambu Betung (Dendrocalamus asper)}

\author{
Tunjung Wahyu Widayati a,1,*, Danang Jaya ${ }^{\mathrm{a}, 2}$, Anantyto Danujatmiko ${ }^{\mathrm{a}, 3}$, Bagus Drajat Trimulyo ${ }^{\mathrm{a}, 4}$ \\ a Teknik Kimia, Universitas Pembangunan Nasional "Veteran” Yogyakarta, Jl. Padjajaran 104 (Lingkar Utara), Condongcatur Yogyakarta 55283 \\ ${ }^{1}$ tunjung@upnyk.ac.id*; ${ }^{2}$ danangjay@upnyk.ac.id; ${ }^{3}$ danujatmiko@gmail.com \\ * corresponding author
}

\section{ARTICLE INFO}

Article history

Received February 18, 2020

Revised June 24, 2020

Accepted June 24, 2020

Keywords

Betung bamboo

Activated carbon

Adsorption

Pyrolysis

\section{ABSTRACT}

Bamboo is one type of grass that is part of non-timber forest products. The chemical properties of bamboo contain cellulose, lignin, pentosan, ash, and silica. To make charcoal from bamboo it is necessary to go through a pyrolysis process. Pyrolysis is a process of thermal decomposition carried out in an inert condition. Pyrolysis gradually encourages the formation of secondary reactions, where after a process occurs, recombination occurs which will produce secondary charcoal. Pyrolysis at high temperatures can cause activated charcoal, which is caused by cracking on the surface of the charcoal thereby increasing the surface area of the charcoal. BET analysis is needed to find out the adsorption power of gas molecules on the surface and to the basis for analysis techniques that are important in the measurement of a certain surface area of the material. The ability of activated charcoal to absorb liquid $N_{2}$ is carried out at $77 \mathrm{~K}$ with the GSA Quantachrome NovaWin. The largest surface area was obtained in this study at a temperature of $800{ }^{\circ} \mathrm{C}$ with pyrolysis time for 3 hours which resulted in a surface area value of $343.9424 \mathrm{~m}^{2} / \mathrm{g}$ of activated carbon. Based on this research, it can be concluded that higher temperatures and the longer pyrolysis time of pyrolysis, the higher value of the surface area that is produced at a certain temperature and time until the carbon pores are damaged.

This is an open access article under the CC-BY-SA license.

\section{Pendahuluan}

Pada berbagai industri yang berkembang di Indonesia, sering muncul masalah yang berkaitan dengan pemurnian gas, seperti gas beracun, bau busuk, dan asap pada industri gas dan pengolahan LNG, bau pada industri obat dan makanan, warna dan rasa yang tidak enak pada industri minuman, serta adanya polutan pada industri pengolahan air. Karbon aktif merupakan suatu padatan berpori yang mengandung $85 \%$ - 95\% karbon, dihasilkan dari bahan-bahan yang mengandung karbon dengan pemanasan pada suhu tinggi. Selain dapat dipakai untuk mengatasi permasalahan industri, karbon aktif dapat juga digunakan sebagai penyimpanan gas (gas adsorptive storage).

Selama ini pengembangan pembuatan karbon aktif sudah dilakukan dengan menggunakan batubara (bituminous coal) dan material organik dengan kandungan karbon yang tinggi seperti tempurung kelapa, serat kayu, dan limbah agrikultur seperti bambu. Bambu merupakan salah satu jenis rumput-rumputan yang termasuk ke dalam famili Gramineae dan merupakan bagian dari komoditas hasil hutan bukan kayu. Bambu sangat potensial sebagai bahan substitusi kayu karena rumpunan bambu dapat terus berproduksi selama pemanenannya terkendali dan terencana. Dari 
kurang lebih 1000 spesies bambu dalam 80 negara, sekitar 200 spesies dari 20 negara ditemukan di Asia Tenggara, sedangkan di Indonesia ditemukan sekitar 60 jenis. Tanaman bambu Indonesia ditemukan di dataran rendah sampai pegunungan dengan ketinggian $300 \mathrm{mdpl}$. Pada umumnya ditemukan di tempat-tempat terbuka dan daerahnya bebas dari genangan air.

Beberapa komposisi kimia bambu meliputi kadar selulosa, lignin, pentosan, abu, dan silika. Kadar selulosa berkisar antara 42,4\% - 53,6\%, lignin 19,8\% - 26,6\%, pentosan 1,24\% - 3,77\%, abu $1,24 \%$ - 3,77\%, dan silika $0,1 \%$ - 1,78\% [1]. Dari komposisi lignoselulosa yang banyak mengandung karbon tersebut terlihat bahwa bambu memiliki kriteria sebagai bahan dasar dari karbon aktif. Kriteria lainnya yaitu bambu sudah cukup tua dengan umur 4 tahun, kandungan air rendah $15 \%$ - 20\%, mudah merengkah sehingga bambu mudah terdekomposisi [2]. Pada penelitian ini akan digunakan bambu betung dari Desa Brajan, Minggir, Sleman sebagai bahan pembuatan karbon aktif. Semakin tinggi suhu maka semakin tinggi luas permukaan, kondisi ini dapat menurun setelah mencapai titik optimum. Suhu maksimum untuk mendapatkan luas permukaan yang besar berada pada suhu $700{ }^{\circ} \mathrm{C}[3]$.

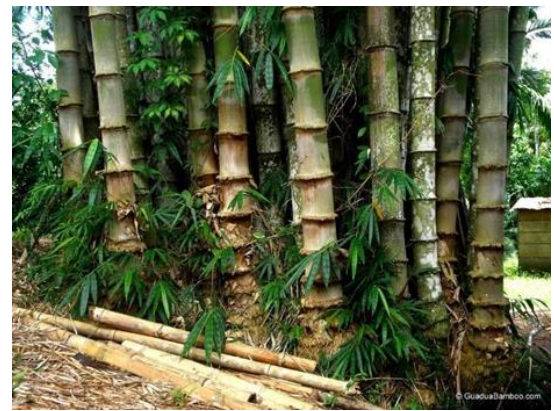

Gambar 1. Bambu Betung

Pirolisis adalah suatu proses pemanasan suatu padatan dengan mengkondisikan lingkungan tanpa kehadiran oksigen untuk membuat produk gas (umumnya $\mathrm{CO}_{2}, \mathrm{H}_{2}, \mathrm{CO}, \mathrm{CH}_{4}, \mathrm{C}_{2} \mathrm{H}_{2}, \mathrm{C}_{2} \mathrm{H}_{4}, \mathrm{C}_{2} \mathrm{H}_{6}$, Benzene, dan lain sebagainya), produk cair (tar, air, dan hidrokarbon rantai panjang), dan padatan (arang). Faktor-faktor yang mempengaruhi proses pirolisis adalah suhu, waktu pirolisis, laju pemanasan, tekanan, jenis bahan baku, ukuran partikel [4]. Penelitian ini menggunakan kondisi suhu pirolisis $500^{\circ} \mathrm{C}, 600{ }^{\circ} \mathrm{C}, 700^{\circ} \mathrm{C}, 800^{\circ} \mathrm{C}$, dan $900^{\circ} \mathrm{C}$ dan waktu pirolisis 1 dan 3 jam.

\section{Metodologi}

Metode BET bertujuan untuk menjelaskan adsorpsi secara fisika dari molekul-molekul gas pada permukaan dan menjadi landasan untuk analisis yang penting pada pengukuran luas daerah permukaan tertentu dari sebuah material. Adsorpsi multilayer disajikan pada Gambar 2. Berikut persamaan BET:

$$
\begin{aligned}
& \frac{1}{W\left(\left(\frac{P}{P o}\right)-1\right)}=\frac{1}{W m C}+\frac{(C-1)}{W m C} \frac{P}{P o} \\
& \frac{1}{W\left(\left(\frac{P}{P o}\right)-1\right)}=\frac{1}{W m C}+\frac{\left(C \frac{P}{P o}-\frac{P}{P o}\right)}{W m C} \\
& \frac{1}{W\left(\left(\frac{P}{P o}\right)-1\right)}=\frac{1+\frac{P}{P o}(C-1)}{W m C}
\end{aligned}
$$




$$
\begin{aligned}
& \frac{1}{W m}=\frac{C}{W\left(\left(\frac{P}{P o}\right)-1\right)\left(1+\frac{P}{P o}(C-1)\right)} \\
& W m=\frac{1}{W\left(\left(\frac{P}{P o}\right)-1\right)\left(1+\frac{P}{P o}(C-1)\right)} \\
& S t=\frac{W m N A c s}{M} \\
& S g=\frac{S t}{w}
\end{aligned}
$$

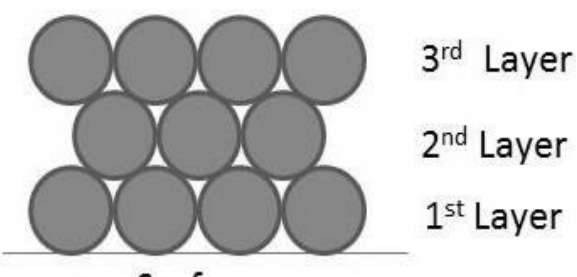

Surface

Gambar 2. Adsorpsi multilayer

\subsection{Alat dan Bahan}

Rangkaian alat pirolisis yang digunakan disajikan pada Gambar 3. Alat yang digunakan adalah mesh Screener, cawan porselen, uantachrome Nova, dan analytical balance. Bahan yang digunakan dalam penelitian adalah: limbah bambu betung bagian pangkal dan gas $\mathrm{N}_{2}$.

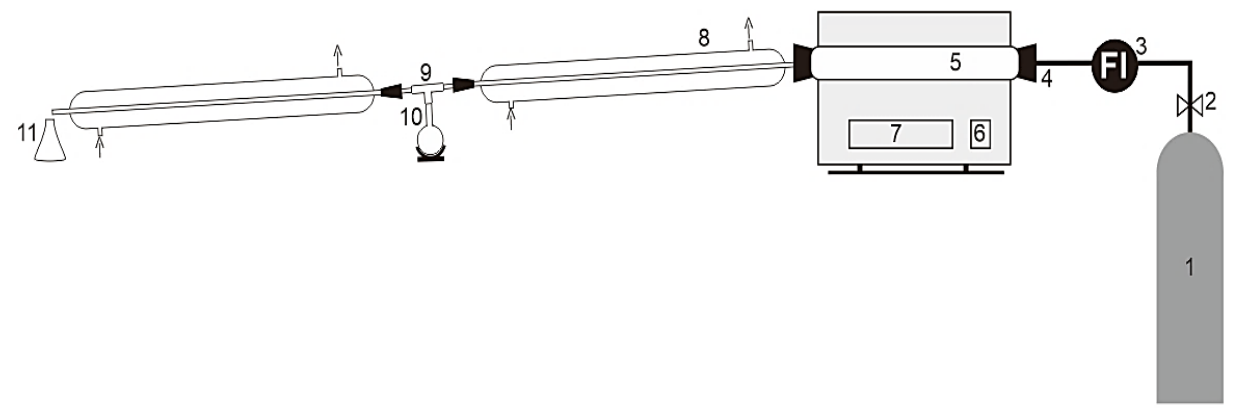

\section{Keterangan:}

1. Tabung $\mathrm{N}_{2}$, 2. Regulator valve, 3. Rotameter, 4. Karet penyumbat, 5. Tabung furnace, 6. Saklar, 7. Panel informasi furnace, 8. Kondensor, 9. Adaptor, 10. Labu, 11. Erlenmeyer

Gambar 3. Rangkaian Alat Pirolisis

\subsection{Metode Penelitian}

Bambu dipotong di bagian dekat akar lalu dibersihkan untuk menghilangkan kotoran dengan pisau parang dan sikat. Bambu yang digunakan pada penelitian ini adalah limbah bambu sisa pemotongan dengan gergaji mesin yang telah diayak dengan ukuran -30 mesh. Selanjutnya bambu betung dikeringkan dengan muffle furnace pada suhu $100^{\circ} \mathrm{C}$ dengan interval waktu 60 menit hingga konstan dengan tujuan untuk menghilangkan kadar airnya.

Sebanyak 150 gram bambu betung yang sudah diayak dengan ukuran -30 mesh, setelah itu dimasukkan ke dalam furnace secara bertahap dengan kapasitas furnace 25 gram per siklus, kemudian melakukan proses pirolisis di dalam furnace dengan suhu $500-900{ }^{\circ} \mathrm{C}$ selama 1 dan $3 \mathrm{jam}$. 
Pirolisis dilakukan dengan mengalirkan gas $\mathrm{N}_{2}$ sebesar $40 \mathrm{ml} /$ menit selama 2 menit sebelum pirolisis dimulai, ini ditujukan untuk menghilangkan kandungan $\mathrm{O}_{2}$ di dalam tabung furnace. Menganalisis kadar abu, kadar air dari arang aktif yang telah dikeringkan, serta menganalisis gugus fungsi yang ada pada adsorben dan pori-porinya dengan BET. Diagram alir proses pirolisis bambu betung disajikan pada Gambar 4.

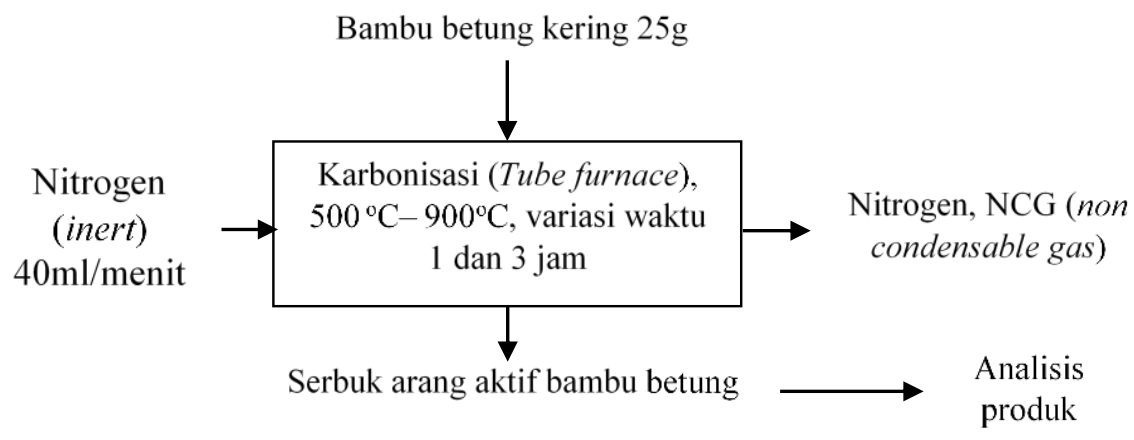

Gambar 4. Diagram alir proses pirolisis bambu betung

\section{Hasil dan Pembahasan}

\subsection{Kadar Air Bambu Betung}

Dari hasil pemanasan sampel bambu betung berukuran -30 mesh yang dilakukan pada suhu 100 ${ }^{\circ} \mathrm{C}$ dengan waktu 240 menit (60 menit per proses pemanasan) hingga dipastikan tidak terjadi penurunan massa. Tiga sampel dengan berat masing-masing 10 gram didapatkan rerata kadar air (\%m) sebesar 18,0167\%. Data kadar air disajikan pada Tabel 1. Kadar air dihitung berdasarkan perbandingan massa yang hilang terhadap massa sampel awal.

Tabel 1. Kadar air bambu betung

\begin{tabular}{|c|c|c|c|c|c|}
\hline \multirow{2}{*}{ Sampel } & \multicolumn{2}{|c|}{ Pemanasan $100^{\circ} \mathrm{C}$} & \multicolumn{2}{|c|}{ Kadar air (\% m) } & \multirow{2}{*}{$\begin{array}{c}\text { Air } \\
\text { teruapkan } \\
\text { (gram) }\end{array}$} \\
\hline & Awal (gram) & Akhir (gram) & $i$ & Rerata & \\
\hline 1 & \multirow{3}{*}{10} & 8,2083 & 17,917 & \multirow{3}{*}{18,0167} & 1,7917 \\
\hline 2 & & 8,1835 & 18,165 & & 1,8165 \\
\hline 3 & & 8,2032 & 17,968 & & 1,7968 \\
\hline
\end{tabular}

\subsection{Luas Permukaan Arang Aktif Bambu Betung}

Pirolisis dilakukan dengan variasi suhu dan waktu mulai dari suhu $500{ }^{\circ} \mathrm{C}$ hingga $900{ }^{\circ} \mathrm{C}$ dengan waktu 1 jam dan 3 jam untuk sampel suhu $800{ }^{\circ} \mathrm{C}$. Pengambilan pirolisis pada waktu 3 jam hanya dilakukan untuk suhu $800{ }^{\circ} \mathrm{C}$ didasari oleh hasil pirolisis yang optimum pada penelitian lain yang menggunakan sampel pirolisis pohon bambu yaitu oleh Horikawa [5] dengan luas permukaan bambu sebesar $391 \mathrm{~m}^{2} / \mathrm{g}$.

\subsection{Rendemen Karbon Hasil Pirolisis Bambu Betung}

Gambar 5 menunjukkan hasil arang pada setiap suhu dengan variasi waktu tinggal. Rendemen arang meningkat dari suhu $500{ }^{\circ} \mathrm{C}$ hingga $800{ }^{\circ} \mathrm{C}$ dan kemudian turun pada suhu $900{ }^{\circ} \mathrm{C}$. Ini sesuai dengan teori yang diungkapkan oleh Zanzi R. [6], dengan judul Pyrolysis of Biomass yang menyebutkan bahwa tar yang dipanaskan lebih lanjut akan berubah menjadi karbon sehingga dapat menghindari terbentuknya abu apabila tidak dipanaskan lebih lanjut.

Penurunan trend grafik di suhu operasi $900{ }^{\circ} \mathrm{C}$ disebabkan oleh rusaknya karbon dari arang bambu betung yang meleleh sehingga micropore dan messopore-nya lengket dan saling menutup. Ini ditunjukkan oleh turunnnya $\%$ massa dari rendemen yang terhitung. Hasil maksimum dicapai pada suhu $800{ }^{\circ} \mathrm{C}$ dengan waktu pirolisis 1 jam dihasilkan rendemen sebesar $24,4988 \%$ dengan massa fixed carbon sebesar 6,1247 gram dari massa sampel kering sebesar 25 gram. 


\subsection{Rendemen Tar Hasil Pirolisis Bambu Betung}

Hasil tar yang paling banyak terjadi pada pirolisis suhu $500{ }^{\circ} \mathrm{C}$ dan $600{ }^{\circ} \mathrm{C}$ dengan volume tar 17 $\mathrm{mL}$. Densitas rerata dari tar bambu didapatkan sebesar $1,1324 \mathrm{gram} / \mathrm{mL}$, disajikan pada Tabel 2 . Nilai ini mendekati densitas dari tar hasil pirolisis dari Vinod [7]. Di bukunya yang berjudul Pavement Materials and Construction yang bernilai dari 1,16 gram $/ \mathrm{mL}$ sampai dengan 1,28 $\mathrm{gram} / \mathrm{mL}$ untuk semua jenis tar.

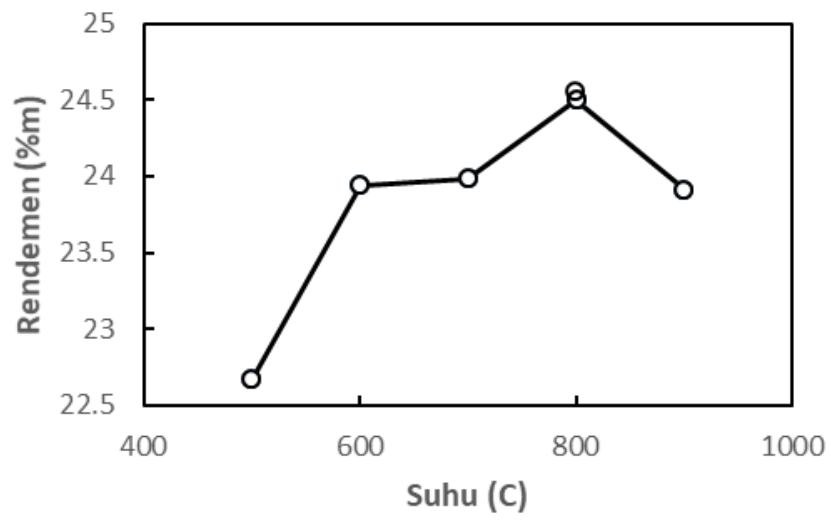

Gambar 5. Grafik rendemen karbon bambu betung terhadap suhu pemanasan pirolisis

Pirolisis bambu betung dengan berbagai suhu dan waktu menghasilkan volume bambu yang berbeda-beda. Tar didapatkan dari zat volatil yang ada di bambu betung yang teruapkan dikarenakannya titik didihnya yang rendah, sehingga tar dapat dilewatkan kondensor dengan tujuan untuk diubah fasanya menjadi cair. Pirolisis bambu betung pada suhu rendah lebih banyak menghasilkan tar daripada pirolisis dengan suhu yang lebih tinggi. Hal ini disebabkan terjadinya reaksi sekunder dari tar berat yang terjadi di dalam furnace. Tar berat terdekomposisi lagi menjadi arang seiring bertambahnya suhu. Tar yang tidak teruapkan akan tetap di dalam furnace dan mengering menjadi padatan karbon ketika suhu ruangan. Hal ini terjadi karena didukung oleh penyusunan tabung furnace yang dijaga tidak terlalu tajam menukik ke bawah, sehingga tar dapat tertahan di dalam furnace untuk meningkatkan fixed cabon-nya.

Tabel 2. Data volume, berat dan densitas dari tar hasil pirolisis bambu betung

\begin{tabular}{cccccc}
\hline \multicolumn{2}{c}{ Sampel } & \multicolumn{2}{c}{ Tar } & \multicolumn{2}{c}{ Densitas $(\mathbf{g} / \mathbf{m L})$} \\
\hline Suhu $\left({ }^{\circ} \boldsymbol{C}\right)$ & Waktu (jam) & Volume $(\boldsymbol{m L})$ & Berat (gram) & $\boldsymbol{i}$ & Rerata \\
\hline 500 & 1 & 17 & 19,242 & 1,1319 & \\
600 & 1 & 17 & 19,243 & 1,1319 & \\
700 & 1 & 15 & 17,03 & 1,1353 & 1,1324 \\
800 & 1 & 12 & 13,584 & 1,1320 & \\
900 & 1 & 9 & 10,188 & 1,1320 & \\
800 & 3 & 9.5 & 10,745 & 1,1311 & \\
\hline
\end{tabular}

\subsection{Analisis Luas Permukaan Arang}

Analisis luas permukaan arang dilakukan pengujian GSA dengan alat Quantachrome NovaWin, disajikan pada Tabel 3 .

Tabel 3. Data luas permukaan spesifik dari arang aktif bambu betung hasil pirolisis

\begin{tabular}{ccc}
\hline Suhu $\left({ }^{\circ} \mathbf{C}\right)$ & Waktu $(\mathbf{j a m})$ & Luas permukaan $\left(\mathbf{m}^{\mathbf{2}} / \mathbf{g}\right)$ \\
\hline 500 & 1 & 79,8183 \\
600 & 1 & 101,0165 \\
700 & 1 & 135,7743 \\
800 & 1 & 186,41894 \\
900 & 1 & 256,8396 \\
800 & 3 & 343,9424 \\
\hline
\end{tabular}




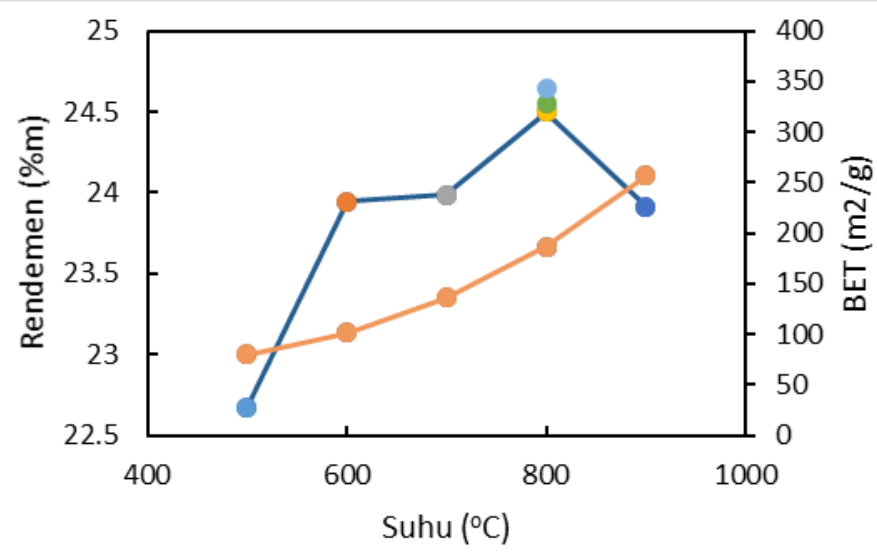

Gambar 6. Grafik suhu pirolisis terhadap rendemen dan luas permuaan spesifik arang aktif hasil pirolisis

Secara umum hubungan luas permukaan dan kapasitas adsopsi adalah linier, yang artinya semakin besar luas permukaan dengan cara membuka pori-pori yang tertutup tar, hidrokarbon dan zat-zat organik lainnya maka kapasitas adsorpsi akan semakin besar juga [8] [9].

Luas permukaan paling besar didapatkan pada keadaan optimum sama seperti penelitian terdahulu yaitu pada suhu $800{ }^{\circ} \mathrm{C}$ dengan waktu pirolisis selama 3 jam yang menghasilkan nilai luas permukaan sebesar 343,9424 $\mathrm{m}^{2} / \mathrm{g}$ karbon bambu betung tersaji pada Gambar 6. Nilai ini sedikit dibawah luas permukaan bambu hasil penelitian [5] Horikawa yang menghasilkan luas permukaan $391 \mathrm{~m}^{2} /$ gram karbon bambu betung.

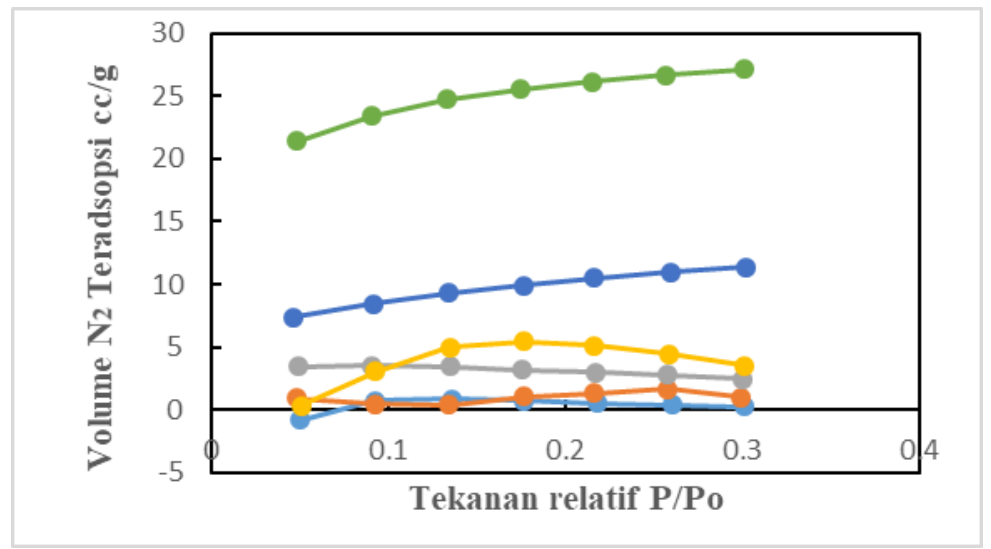

Gambar 7. Grafik $\mathrm{N}_{2}$ teradsorbsi pada arang aktif terhadap tekanan relatif

Gambar 7 menunjukkan nilai (kemampuan) volume $\mathrm{N}_{2}$ yang teradsorpsi pada permukaan arang bambu betung. Nilai $\mathrm{N}_{2}$ yang teradsorpsi mempunyai trend yang naik sejalan dengan naiknya tekanan relatif. Pada waktu pirolisis 3 jam menunjukkan adanya kenaikan yang signifikan pada nilai $\mathrm{N}_{2}$ yang teradsorpsi. Hal ini sesuai dengan teori adanya pengaruh waktu pirolisis pada pembentukan pori-pori arang [10] [11].

Kondisi pirolisis dengan suhu $800{ }^{\circ} \mathrm{C}$ dan waktu pirolisis 3 jam menunjukkan nilai optimum pada kapasitas karbon untuk menjerap Nitrogen. Titik optimumnya berada pada tekanan relatif 0,300521 dengan kemampuan adsorpsi sebesar $27,1036 \mathrm{~cm}^{3} / \mathrm{g}$ karbon bambu betung. Garis suhu adsorpsi Nitrogen pada $77 \mathrm{~K}$ untuk arang bambu betung hasil pirolisis pada berbagai suhu dan waktu identik dengan garis suhu adsorpsi fisik IUPAC, bentuk garis dapat dikategorikan dalam jenis I seperti terlihat pada Gambar 8, yang artinya struktur pori didominasi oleh pori-pori mikro. 


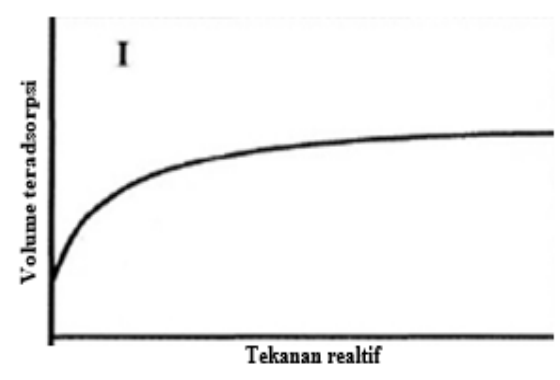

Gambar 8. Grafik adsorbsi jenis I

\section{Kesimpulan}

Semakin tinggi suhu pirolisis dan waktu pirolisis maka fixed carbon yang didapatkan akan semakin banyak, hal ini sesuai dengan titik optimum dari penelitian ini pada suhu $800{ }^{\circ} \mathrm{C}$ dengan waktu pirolisis selama 3 jam. Kapasitas adsorpsi karbon terhadap $\mathrm{N}_{2}$ pada suhu $77 \mathrm{~K}$ optimum pada luas permukaan maksimum yang terbentuk yaitu pada kondisi operasi suhu $800{ }^{\circ} \mathrm{C}$ dengan waktu pirolisis 3 jam.

\section{Notasi}

$\mathrm{C}=$ Konstanta BET

Po = Tekanan uap jenuh gas yang diasorpsi pada suhu eksperimen $(\mathrm{kPa})$

$\mathrm{P} \quad=$ Tekanan total gas saat adsorpsi $(\mathrm{kPa})$

$\mathrm{Wm}=$ Berat gas teradsorb untuk monolayer $(\mathrm{g})$

$\mathrm{W}=$ Berat gas yang diadsorpsi pada tekanan $\mathrm{P}(\mathrm{g})$

$\mathrm{N}=$ Bilangan Avogadro $=6,022 \times 10^{23}$

Acs = Luas penampang satu molekul adsorbat $\left(\mathrm{m}^{2}\right)$

$\mathrm{M}=$ Berat Molekur (g/gmol)

$\mathrm{W} \quad=$ Berat sampel $(\mathrm{g})$

$\mathrm{St}=$ Total surface area $\left(\mathrm{m}^{2}\right)$

$\mathrm{Sg}=$ Luas permukaan adsorben/berat adsorben $\left(\mathrm{m}^{2} / \mathrm{g}\right)$

\section{Daftar Pustaka}

[1] Krisdianto, "Analisa sifat-sifat arang dari tiga jenis bambu", Warta Balai Industri Banjarbaru, Vol. XXII No. 2, Desember 2007

[2] Shenxue, Jiang, "Taining manual of bamboo charcoal for producers and consumers", Nanjing: Nanjing Forestry University, 2004.

[3] Pujiyanto, "Pembuatan karbon aktif super dari batubara dan tempurung kelapa", Tesis FT UI Dept. Teknik Kimia Depok, 2010.

[4] Luo, S., Feng, Y., "The production of fuel oil and combustible gas by catalytic pyrolysis of waste tire using waste heat of blast-furnace slag", Energy Convers, Manag. 136, 2017, 27-35.

[5] Horikawa, "Humudity control capacity of activated carbon from bamboo", Dept. of Advanced Materials University of Tokushima and Dept. of Chemical, Energy and Environmental Engineering Kansai University Japan, 2010.

[6] Zanzi R., "Pyrolysis of biomass: rapid pyrolysis at high temperature slow pyrolysis for active carbon preparation”, KTH Royal Institude of Technology, 2001.

[7] Vinod B. R., "Pavement materials and construction", BMS Institure of Technology and Management, 2010.

[8] Albright, Lyle F, “Albright's chemical engineering handbook”, CRC Pressm, Boca Raton, 2009.

[9] Ketaren, S., "Introduction of essential oil technology", Jakarta: Balai Pustaka, 1987, 01(19-20): 286299.

[10] Lua, A.C \& Gio, J., “Allbright’s chemical enginerring handbook”, USA: CRC (Press), 1998. 
[11] Wang Jun Fu-An, Meng W., N. Oium Yao L., S.Q. Fang, dan Xing J., "Preparation of activated carbon from a renewable agricultural residue of pruning mulberry shoot", African Journal of Biotechnology, Vol.9(19), 2010.

[12] Ryu, Z., Zheng, J. Wang, M., Zhang, B., "Characterization of pore size distributions on carboneaceus adsorbents by DFT". Carbon 37: 1257-1264, 1999. 